ORIGINAL ARTICLE

\title{
Twin frequency and industrial pollution in different regions of Hesse, Germany
}

\author{
N Obi-Osius, B Misselwitz, W Karmaus, J Witten
}

Occup Environ Med 2004;61:482-487. doi: 10.1136/oem.2003.008342

See end of article for authors' affiliations

....................

Correspondence to: Dipl. Biol. N Obi-Osius, Epidemiological Working Group, Ministry of Environment and Health and the Institute for Medical Biometry and Epidemiology, University Hospital HamburgEppendorf, Winterhuder Weg 29, 22085 Hamburg, Germany; osius@uke.unihamburg.de

Accepted

28 November 2003

\begin{abstract}
Aims: To investigate whether twinning occurs more frequently in residents in the vicinity of a toxic waste incinerator (TWI).

Methods: Within a longitudinal environmental study that addressed child health second grade school children and their parents were recruited. The proportion of twinning in the TWI region was compared with two comparison areas. In a second confirmatory investigation, birth records for the years 1994-97 from the Hessian Perinatal Survey (HEPS) were accessed to determine whether the incidence of twinning was higher in regions around the TWI compared to adjacent reference areas.

Results: In the environmental study, $61.5 \%$ of the children and $95 \%$ of their mothers participated. In mothers, twinning was $5.3 \%$ in the TWI region compared to $1.6 \%$ and $2.3 \%$ in the comparison regions. The proportion of mothers with fertility assessment/treatment was $5.7 \%, 8.3 \%$, and $0 \%$ respectively. The prevalence of twinning was not significantly higher $(4.5 \%)$ in mothers with treatment compared to mothers without (3.7\%). From the HEPS, data of 20603 births was analysed. The incidence of twins was significantly higher in areas which surround the TWI and other industries (1.4-1.6 per 100 births) compared to births in reference areas (0.8 per 100).

Conclusions: Twinning rates may be associated with exposure to industrial pollution. Future environmental health studies that consider multiple births as an outcome are warranted. These should also investigate whether the incidence of monozygotic or dizygotic twinning may be associated with industrial pollution.
\end{abstract}

$\mathrm{T}$ he majority of multiple births are twins. ${ }^{12}$ Spontaneous winning rates vary due to various determinants including mother's age, parity, ethnicity, genetic, and environmental factors. ${ }^{3}$ Regional, seasonal, and time trends for differences in twin rates have been reported. ${ }^{4-6}$ Only a few studies have addressed the potential association between waste incineration and twinning rates. ${ }^{7-9}$

In developed countries rates for monozygotic twinning have remained relatively constant over time and population, whereas dizygotic twinning (DZ) rates have declined in past decades until the end of the 1970s. ${ }^{10-12}$ Since then an increased incidence of DZ has been observed, probably due to the widespread use of ovulation induction treatment and assisted reproductive technologies as well as higher maternal ages. ${ }^{6} 1314$

Multiple births are associated with higher risks for mother and child, such as shorter gestation, preterm delivery, low birth weight, perinatal death, social challenges. ${ }^{15-17}$

Our hypothesis was that frequency of twin births is higher in women residing in an area environmentally affected by toxic waste incineration and other industries. The exposed study region is situated in the east Rhine Valley with several municipalities located around a toxic waste incinerator (TWI) and industrial sites. This region is also intensively used for agriculture, including home grown food. One comparison region is $20 \mathrm{~km}$ north of the incinerator in the Rhine Valley and is also characterised by industrial and agricultural production (Rhine Valley control, RVC). The third region is located in the southeast behind low mountains that separate it from the industrial area (Odenwald control, OWC).

To test the hypothesis, we used a two staged approach. Initially, we investigated whether women residing around the TWI had a higher prevalence of twin births. As part of a longitudinal study in children, we conducted a crosssectional reproductive survey in their mothers, including a retrospective ascertainment of past pregnancies and fertility treatments. ${ }^{18}$ After preliminary reports, it was questioned whether our findings could be generalised to birth experiences in that region. Hence, we supplemented our study with a second investigation and examined perinatal data that are routinely collected by the Hessian Perinatal Survey (HEPS). ${ }^{19}$ We analysed HEPS data using postal codes of the residence as a proxy measure for exposure to the TWI.

\section{METHODS}

Environmental epidemiological study on reproduction Study population

After obtaining permits from the Data Protection Agency, the human subject review board, the Ministry of Cultural Affairs of Hesse, and from the local school committees, parents of all 1091 second grade school children in 18 townships were asked to participate in a human biomonitoring study. The townships/primary schools were selected with respect to the willingness of the local school committees to cooperate. Furthermore, in each school at least one complete 2nd grade school class was expected to participate. After informed consent, we recruited children and their mothers from nine townships/schools in the TWI, five in the RVC, and four in the OWC region (fig 1). All mothers were asked to participate in the interview on reproduction.

\section{Questionnaire}

We interviewed the mothers on their reproductive history in 1994-95 with a standardised questionnaire that has been used in the European Study on Infertility and Sterility (ESIS). ${ }^{20}$ We determined outcomes of each pregnancy,

Abbreviations: DZ, dizygotic twinning; EES, environmental epidemiological study; ESIS, European Study on Infertility and Sterility; HEPS, Hessian Perinatal Survey; MZ, monozygotic twinning; OWC, Odenwald control; PCA, postal code area; RVC, Rhine Valley control; TWI, toxic waste incinerator 
Main messages

- Twin births have been considered to be associated to environmental pollution.

- This population based study suggested that women residing adjacent to a toxic waste incinerator have a higher lifetime prevalence of twinning

- Analysis of Perinatal Survey data support the findings of the population based investigation: there is a higher incidence of twinning in more industrialised postal code areas.

fertility problems, and whether the mother or her partner ever searched for medical help to conceive. The mothers were also asked about their age at childbirth, parity, and nationality (German or otherwise).

\section{Perinatal survey data}

Data collection and study design

The Perinatal Surveys, established in all federal states of Germany, serve quality assurance purposes in obstetrics and neonatology. The HEPS is a nearly complete investigation of deliveries and births from all obstetric clinics in the state of Hesse. The data include information on pregnancy, mode of delivery, and medical condition of the newborn and the mother. ${ }^{21}$

In cooperation with the Hessian Institute of Quality Assurance, which is responsible for management and analysis of HEPS, and after obtaining permission from their Board of Experts, we analysed HEPS data covering the years 1994-97 from all participating hospitals. During this period in the whole state of Hesse, three obstetric departments with up to 2000 births per year did not contribute to the HEPS since participation in the Perinatal Survey was voluntary up to the year 1997. Two of these hospitals were located in the north of Hesse and one in Frankfurt. Additionally, home deliveries were not reported in the HEPS (estimated 500-1200 per year). Thus, the data included $94.9-96 \%$ of all births in Hesse (approximately 60000 per year).

Within HEPS, residences of women who delivered are coded with a five digit postal code. For reasons of protection of privacy only the first three digits can be used for statistical analysis. To assign each woman to one of the regions covered in the environmental epidemiological study (EES), we used postal codes of the 18 townships. For our study, we included pregnancy data from the Perinatal Survey whenever the maternal residence at time of delivery had the same first three digits of the postal code. Out of the complete HEPS from 1994 to 1997 (236 383 births), data sets from 6133 children $(2.6 \%)$ could not be assigned to any of the three digit postal codes, probably due to changes in coding patterns in 1994.

Some communities in the TWI and RVC regions that participated in the EES share the same three digit postal code. To separate the TWI and RVC region by postal codes in the best possible way we assigned these two EES regions to four postal code areas (PCA 1-4, fig 1). Postal code area 1 (PCA 1) covered the north of the Rhine-Valley, including the RVC group. The neighbouring, southeastwards PCA 2 included a mixed group with townships from the RVC region and TWI region. The hazardous waste incinerator is located in this area (fig 1). Eastwards, adjacent to PCA 2, PCA 3 covered parts of the TWI region. PCA 4 was divided into smaller parts, of which only the most eastern part included one township of the TWI region. The Odenwald control group (OWC) belonged to two PCAs (5 and 6), which were
Policy implications

- In order to assess the impact of the industrial environment on reproductive health, further research on the association of multiple births and pollution is warranted.

combined to one reference in statistical analysis because of small numbers in area 6.

In this part of the study, we investigated whether twin births were more frequent in industrialised regions of the Rhine Valley (PCAs 1-4) than in the combined reference region in the Odenwald (PCAs 5-6), with little or no industry. Triplet births were excluded from the analyses.

\section{Statistical analysis}

For HEPS data and separately for each year, we tested differences in the twinning incidence in each of the PCAs compared to the reference using $\chi^{2}$ tests. We applied multiple logistic regression for the pooled data (1994-97), adjusting for mother's age (years), parity (nulliparous, primiparous, multiparous), and nationality (German versus non-German). Statistical analysis of the reproductive data from the environmental epidemiology study was conducted with

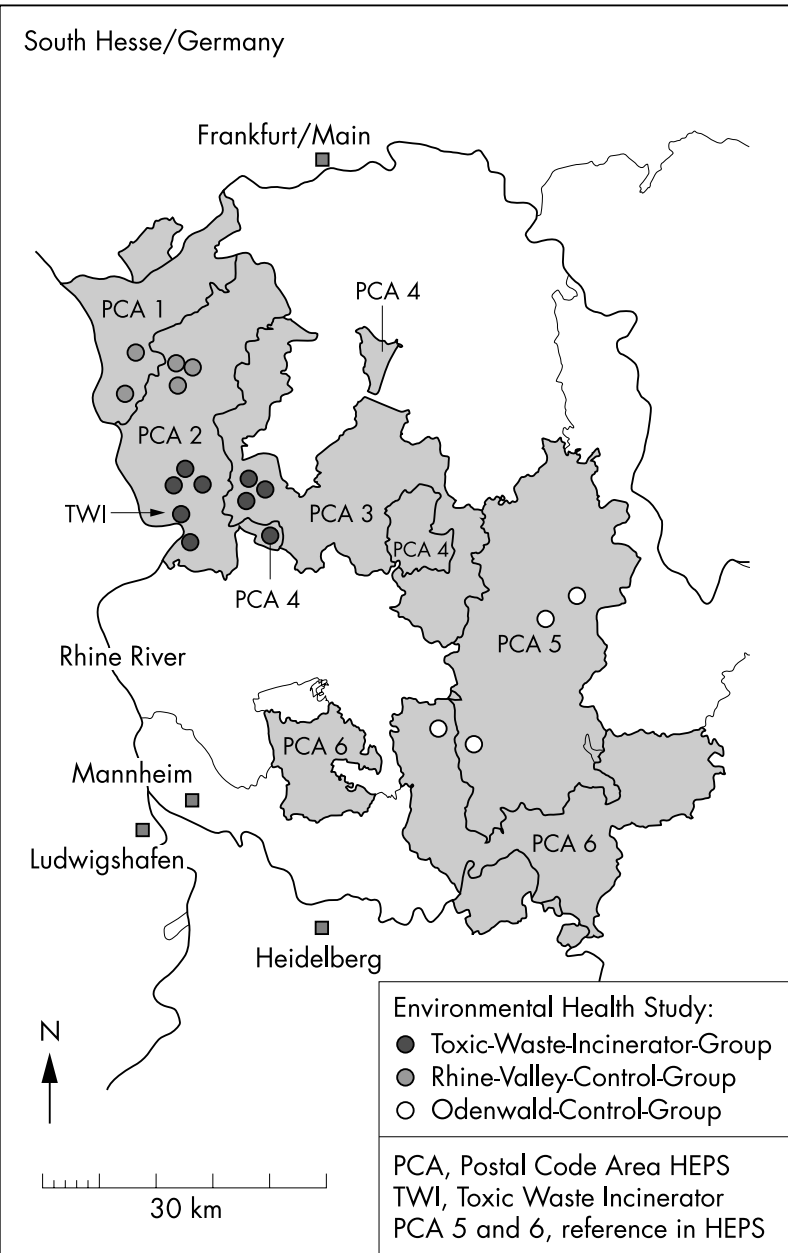

Figure 1 Location of townships in the environmental health study, and six postal code areas in South Hesse to assign residence of twin mothers (Hessian Perinatal Survey 1994-97). 


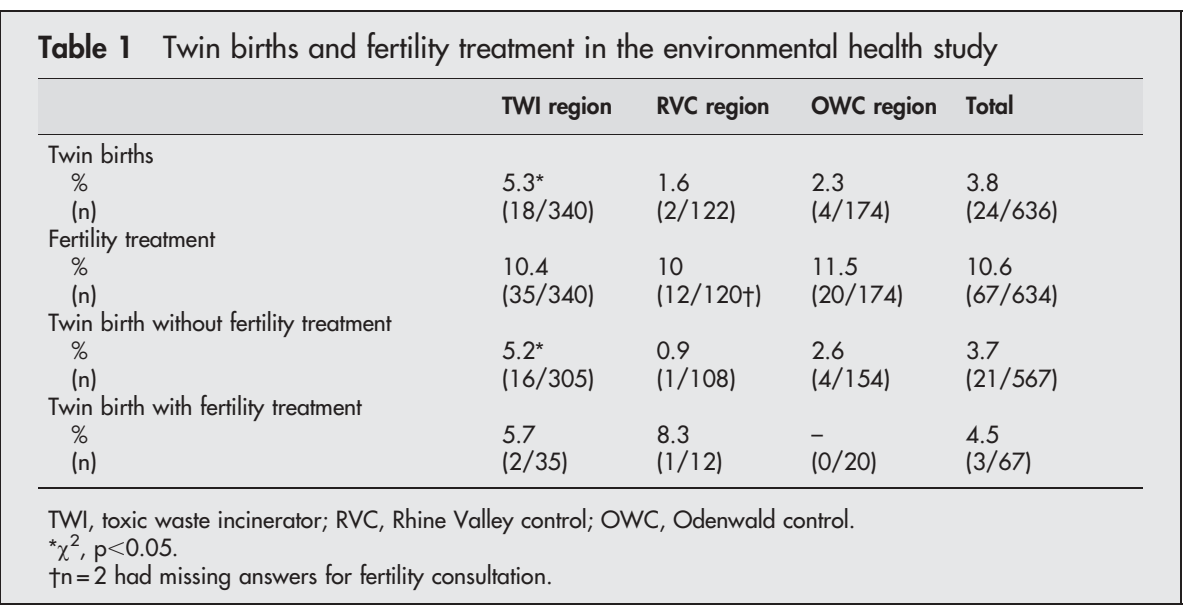

SAS, ${ }^{22}$ while the HEPS data were computed with SPSS for Windows. $^{23}$

\section{RESULTS}

\section{Environmental epidemiological study}

Of the 1091 second grade children in the 18 communities, 671 participated $(61.5 \%)$. Reproductive interviews were conducted with 639 mothers $(95.2 \%)$. Of these, three mothers were never pregnant, and one mother was pregnant but did not have a live child. Maternal age at time of the interview ranged from 26 to 49 years; $90.7 \%$ of the mothers were German and 9\% were of another nationality.

Twin births had occurred in 23 mothers, and one mother had two occurrences of twin births. Of the mothers residing in the TWI region $5.3 \%$ had twins $(\mathrm{n}=18), 1.6 \%$ in the RVC region $(n=2)$, and $2.3 \%$ in the OWC region $(n=4)$ (table 1$)$. For fertility assessment or treatment no differences were identified in the three regions (table 1). Of the mothers who underwent fertility treatment in the TWI region, 5.7\% (2 of 35 ) gave birth to twins, compared to $5.2 \%$ ( 16 of 305) of the mothers in this region who did not undergo fertility treatment. With respect to the total group, the prevalence of twinning is not significantly higher in the mothers who were medically assisted (4.5\%) versus mothers who were not
(3.7\%). If only mothers with spontaneous twinning were included in the analysis, the regional differences with higher twinning frequency in the TWI region persisted (table 1).

\section{Perinatal survey data}

The sample covered approximately $93 \%$ of all deliveries with postal codes in the region of interest in South Hesse. Some pregnant women residing in the selected PCAs might have delivered in Heidelberg, which is located in the neighbouring federal state of Baden-Württemberg (fig 1 ). The number of births from 1994 to 1997 in each PCA ranged from approximately 300 to 1700 per year (table 2 ).

We observed significant differences in twinning frequencies to the reference area in PCA 1 in 1997 and in PCA 2 in 1995 and 1996 (fig 2). Also after pooling the data from 199497, we noted that twin births were significantly more frequent in PCA 1, 2, and 3 which were part of the industrialised Rhine Valley* compared to the combined reference areas 5 and 6 corresponding to the Odenwald (table 2, fig 1). Triplets $(n=6)$ occurred only in PCA 2 in 1995 and $1996(\mathrm{n}=1$ and $\mathrm{n}=2$, respectively), as well as in

*The whole area along the River Rhine is meant here, not only the RVC.

Table 2 Distribution of mother's births characteristics in six postal areas of South Hesse (Hessian Perinatal Survey)

\begin{tabular}{|c|c|c|c|c|c|c|}
\hline & $\begin{array}{l}\text { Postal } \\
\text { area } 1\end{array}$ & $\begin{array}{l}\text { Postal } \\
\text { area } 2\end{array}$ & $\begin{array}{l}\text { Postal } \\
\text { area } 3\end{array}$ & $\begin{array}{l}\text { Postal } \\
\text { area } 4\end{array}$ & $\begin{array}{l}\text { Postal } \\
\text { area 5/6 }\end{array}$ & Total \\
\hline \multicolumn{7}{|l|}{ Number of births ( $n$ ) } \\
\hline 1994 & 1278 & 927 & 1630 & 248 & 849 & 4932 \\
\hline 1995 & 1373 & 938 & 1643 & 303 & 803 & 5060 \\
\hline 1996 & 1469 & 1057 & 1684 & 321 & 820 & 5351 \\
\hline 1997 & 1282 & 1008 & 1715 & 334 & 921 & 5260 \\
\hline Total no. & 5402 & 3930 & 6672 & 1206 & 3393 & 20603 \\
\hline Mean maternal age (y) & 28.88 & 29.14 & 29.42 & 29.59 & 28.74 & 29.12 \\
\hline (SD) & (5.07) & $(4.88)$ & $(4.76)$ & (4.54) & (5.05) & (4.91) \\
\hline \multicolumn{7}{|l|}{ Parity (\%) } \\
\hline 0 & 48.6 & 49.5 & 50.0 & 46.8 & 45.7 & 48.7 \\
\hline 1 & 35.4 & 35.4 & 35.9 & 39.1 & 36.9 & 36.0 \\
\hline$\geqslant 2$ & 16.0 & 15.1 & 14.1 & 14.1 & 17.4 & 15.3 \\
\hline Parity: $\chi^{2}$ test ( $p$ value) & 0.023 & 0.002 & 0.000 & 0.028 & reference & \\
\hline German women (\%) & 66.4 & 73.1 & 80.4 & 86.6 & 75.4 & 74.9 \\
\hline \multicolumn{7}{|l|}{ Twin births (\%) } \\
\hline 1994 & 1.0 & 1.4 & 1.5 & 0.8 & 0.8 & 1.2 \\
\hline 1995 & 1.0 & 1.5 & 1.0 & 1.3 & 0.5 & 1.0 \\
\hline 1996 & 1.6 & 2.1 & 1.5 & 0.9 & 0.7 & 1.5 \\
\hline 1997 & 2.4 & 1.3 & 1.6 & 2.1 & 1.0 & 1.7 \\
\hline Total & 1.5 & 1.6 & 1.4 & 1.3 & 0.8 & 1.4 \\
\hline Total: $\chi^{2}$ test ( $p$ value) & 0.002 & 0.001 & 0.006 & 0.079 & reference & \\
\hline Triplet births (\%) & - & 0.1 & 0.04 & - & - & 0 \\
\hline
\end{tabular}




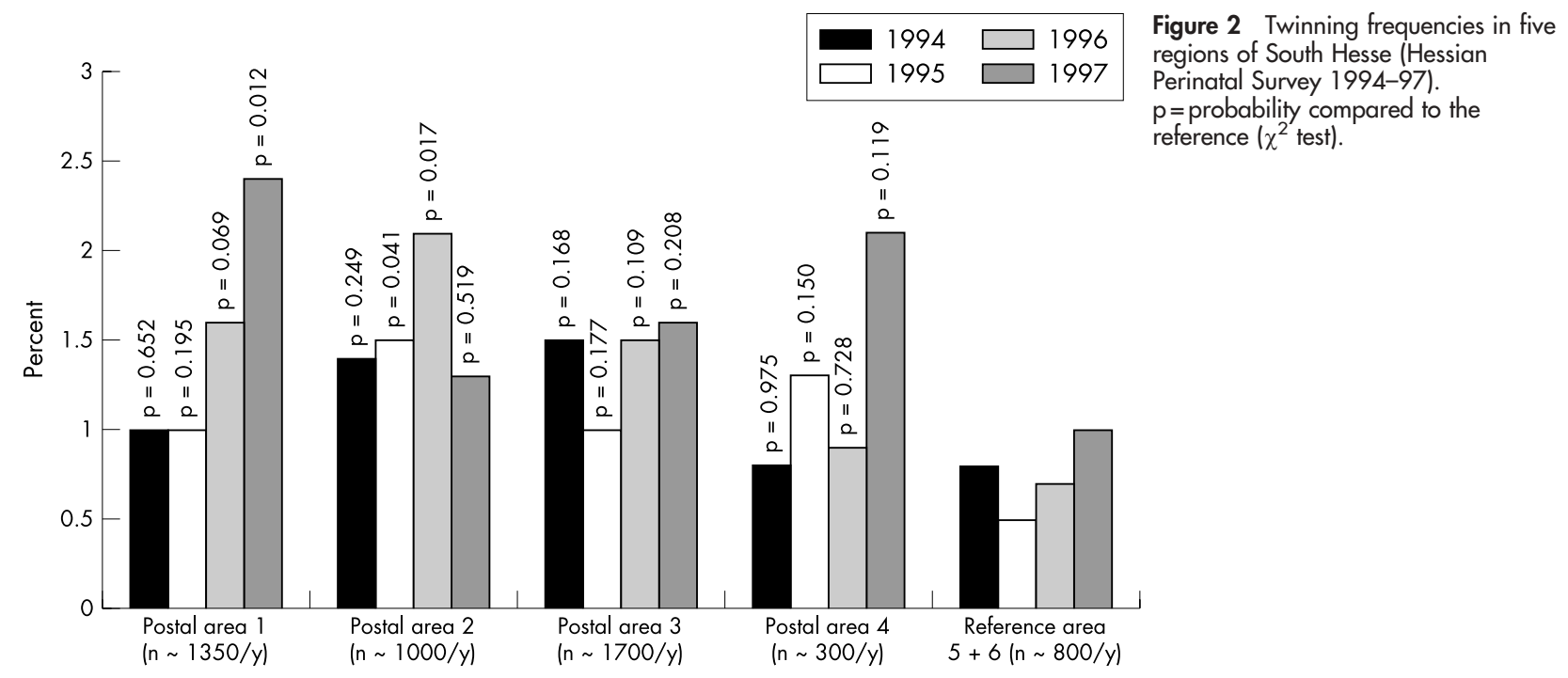

PCA 3 in 1994 and 1996 ( $\mathrm{n}=1$ and $\mathrm{n}=2$, respectively). Higher order multiple births were not reported.

For logistic regression analyses, we pooled data of the four years and excluded triplets. We statistically controlled for mother's age, parity, and nationality. In the industrialised PCA 2, where the TWI is located, twins were born twice as often as in the reference area (OR $=2.03,95 \%$ CI 1.28 to 3.22 , fig 3, table 3); this difference is significant. Mother's age at birth was a significant risk factor; each additional year increases the OR by 1.04 (95\% CI 1.01 to 1.07). Primiparous women showed a non-significant lower risk for twinning ( $\mathrm{OR}=0.78,95 \%$ CI 0.59 to 1.02 ), whereas in multiparae the odds ratio decreased significantly compared to nulliparae $(\mathrm{OR}=0.62,95 \%$ CI 0.42 to 0.93$)$. Twinning was not statistically significantly associated with nationality $(\mathrm{OR}=1.05$, 95\% CI 0.78 to 1.41 ).

\section{DISCUSSION}

First, the environmental investigation supported our hypothesis that residing in the vicinity of a toxic waste incinerator may be associated with more multiple births. Second, Perinatal Survey data (HEPS) provided additional evidence of an increased relative risk of twinning in this region comparing industrialised versus less industrialised postal code areas (PCAs).

Information from the mothers of the second grade children (7-10 years) who participated in the environmental study (1994-95) represented their lifetime prevalence of twinning. Maternal age and the recall period did not differ systematically between the three regions in the environmental study, corresponding to the fact that all mothers had at least one child in the second grade. Thus, there is no indication that a selection or information bias might have caused the observed differences. Compared to the perinatal data, the time window in the environmental epidemiological study, however, was wider than the time window of the HEPS (1994-97) and represented events that occurred before 1995. Hence, with regard to the time window, both parts of the investigation are supplemental.

For the perinatal analysis, we only had a proxy criterion (a three digit postal code) to define residence in the exposed region. Thus, findings based on the HEPS suffer from exposure misclassification that is likely to introduce an underestimation of the association of interest. Nevertheless, the presented data indicate that residing in an industrial area may be a risk for multiple births. In this respect, it is of importance that the Rhine Valley, a diameter of approximately $30 \mathrm{~km}$, is bordered with low mountains on both sides. The region frequently has an inversion layer so that air pollution remains in the valley. Following the main wind direction in the Rhine Valley, air pollution travels from south to north, from heavily industrialised regions around Mannheim and from the TWI region to the PCA 1 and 2, and western parts of PCA 3 (fig 1).

The higher incidences of twinning are greatly consistent over the four birth cohort years (1994-97). Additionally, it is remarkable that in two of the four potentially exposed PCAs, the incidence of twinning increased from 1994 to 1997 (fig 2).

A limitation of the environmental study is that we did not further specify the diagnostic fertility procedures or treatments. There is evidence that ovulation induction and assisted reproduction are the main contributors to increasing rates of multiple births. ${ }^{15}{ }^{14}$ However, there is no reason to suspect that the use of fertility services is a confounder since it is equally distributed in the three EES regions of interest (table 1). If only the mothers without a history of reproductive medical assistance are considered, the prevalence of spontaneous twinning was highest in the TWI region as well. It seems unlikely that assisted reproduction contributes to our findings in the EES.

In the HEPS data both spontaneous and assisted twin births were included, since information about ovulation induction therapy, assisted reproductive techniques, and medication was not provided. Consequently, neither rates of induced versus spontaneous twinning nor possible regional differences in utilisation of assisted reproduction

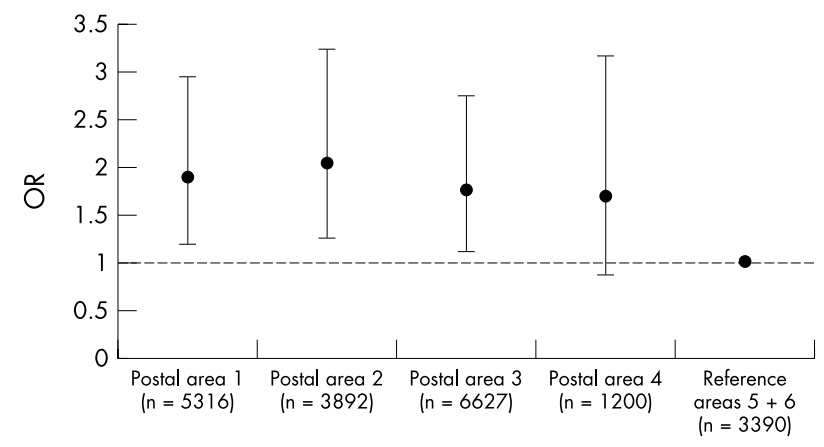

Figure 3 Odds ratios and $95 \%$ confidence intervals for twin births adjusted for age of the mother, parity, and nationality in five regions of South Hesse (data from Hessian Perinatal Survey pooled for 1994-97). 
Table 3 Adjusted logistic model on frequency of twinning in different postal code areas of South Hesse (20 425 mothers, 275 mothers of twins)

\begin{tabular}{|c|c|c|c|c|c|c|}
\hline & \multirow[b]{2}{*}{$\mathbf{n}$} & \multirow[b]{2}{*}{ df } & \multirow[b]{2}{*}{$p$} & \multirow[b]{2}{*}{ Odds ratio } & \multicolumn{2}{|c|}{$95 \% \mathrm{Cl}$} \\
\hline & & & & & Lower & Upper \\
\hline Postal code area & & 4 & 0.042 & & & \\
\hline PCA $(5+6)$ & 5316 & & & reference & & \\
\hline PCA (1) & 3892 & 1 & 0.005 & 1.889 & 1.208 & 2.953 \\
\hline PCA (2) & 6627 & 1 & 0.003 & 2.032 & 1.282 & 3.220 \\
\hline PCA (3) & 1200 & 1 & 0.011 & 1.767 & 1.141 & 2.737 \\
\hline PCA (4) & 3390 & 1 & 0.101 & 1.689 & 0.902 & 3.162 \\
\hline Mother's age (years) & 20425 & 1 & 0.007 & 1.037 & 1.010 & 1.065 \\
\hline Parity & & 2 & 0.033 & & & \\
\hline Nulliparae & 9933 & & & reference & & \\
\hline Primiparae & 7358 & 1 & 0.065 & 0.778 & 0.595 & 1.016 \\
\hline Multiparae & 3134 & 1 & 0.019 & 0.621 & 0.417 & 0.926 \\
\hline \multicolumn{7}{|l|}{ Nationality } \\
\hline German & 15299 & & & reference & & \\
\hline Not German & 5126 & 1 & 0.748 & 1.050 & 0.781 & 1.412 \\
\hline Constant & 1 & 1 & 0.000 & 0.003 & & \\
\hline
\end{tabular}

could be assessed from these data. However, we excluded mothers with triplets from the analyses of HEPS data due to the probability of a higher proportion of ovulation induction or assisted reproduction techniques leading to higher order multiple births. ${ }^{13}$ Between 1994 and 1997 only six triplets were born in PCA 2 and 3. With inclusion of these mothers the estimated odds ratios for multiple births do not change essentially (changes in OR from 2.03 to 2.10 in PCA 2 and from 1.77 to 1.82 in PCA 3 ). Given the rare occurrence of spontaneous higher order multiples, the finding might indicate a higher proportion of assisted twinning in the industrialised regions of PCA 2 and 3 compared to the other PCAs but it would not explain the magnitude and higher twinning rate in PCA 1. Additionally, in HEPS no information was available on potential migration for delivery of multiples to neighbouring federal states.

Another limitation is that both data sources do not provide information on whether the twins were monozygotic or dizygotic. It is likely that DZ increased, as monozygotic twinning (MZ) rates seemed to remain constant over time, ${ }^{35}$ or increase only slightly. ${ }^{24}$

Multiple births are rarely investigated in environmental health studies. ${ }^{9}$ The evidence of increased incidence of multiple births around waste incinerators is not consistent. In Scotland in the early 1980s women around two hazardous waste incinerators showed higher twinning rates. ${ }^{72}$ In Belgium, investigators found a 2.6-fold higher probability of having multiple births among inhabitants near household waste incinerators. ${ }^{26}$ A Swedish study found no general increase of twin births around 14 incinerator plants before and after commissioning. ${ }^{8}$

In conclusion, considering the increased health risks of multiple births, such as preterm delivery, lower birth weights, and a higher perinatal mortality, ${ }^{2}$ the suggested associations between exposure to industrial pollutants, in particular incineration facilities, and the increase in twinning rate emphasise the importance of future investigations. Also, an increase in the incidence of multiple births may reflect the impact of exposure to environmental factors, that might also have other hidden health effects. We suggest further employment of existing data sources such as the Perinatal Surveys or birth registries. Additionally, there is a need to improve exposure approximation. Even without reidentifying individual births, it should be possible to provide more detailed postal code information for statistical analyses as was shown elsewhere. ${ }^{27}$ Further, information about the type of twins (monozygotic or dizygotic) can provide understanding on whether endocrine disruption due to environmental exposure, ${ }^{28} 29$ potentially resulting in more $\mathrm{DZ}^{30}{ }^{31}$ or rather environmental stress to the oocyyte, leading to $\mathrm{MZ}$, may explain the association. More generally, our findings point to the importance of further biomonitoring studies on the health impact of environmental pollution which should include not only exposure but also effect parameters.

\section{Authors' affiliations}

N Obi-Osius, Epidemiological Working Group of the Ministry of Environment and Health and the Institute for Medical Biometry and Epidemiology, University Hospital Hamburg-Eppendorf, Germany B Misselwitz, Institute of Quality Assurance of Hesse, Eschborn/ Frankfurt, Germany

W Karmaus, Department of Epidemiology, Michigan State University, East Lansing, USA

J Witten, Ministry of Social Welfare of Hesse, Department of Health, Wiesbaden, Germany

Financial support: The study was authorised and supported by the former Ministry of Environment, Energy, Youth, Family and Health Hesse, Germany

\section{REFERENCES}

1 Murphy MF, Hey K, Whiteman D, et al. Is the natural twinning rate now stable? J Biosoc Sci 2000;32:279-81.

2 Keith LG, Oleszczuk JJ, Keith DM. Multiple gestation: reflections on epidemiology, causes, and consequences. Int J Fertil Womens Med 2000;45:206-14.

3 Bortolus R, Parazzini F, Chatenoud L, et al. The epidemiology of multiple births. Hum Reprod Update 1999;5:179-87.

4 Nylander PP. The factors that influence twinning rates. Acta Genet Med Gemellol (Roma) 1981;30:189-202.

5 Westergaard T, Wohlfahrt J, Aaby P, et al. Population based study of rates of multiple pregnancies in Denmark, 1980-94. BMJ 1997;314:775-9.

6 Imaizumi Y. Trends of twinning rates in ten countries, 1972-1996. Acta Genet Med Gemellol (Roma) 1997;46:209-18.

7 Lloyd OL, Lloyd MMM, Williams FLR, et al. Twinning in human populations and in cattle exposed to air pollution from incinerators. BMJ 1988;45:556-60.

8 Rydhstroem H. No obvious spatial clustering of twin births in Sweden between 1973 and 1990. Environ Res 1998:76:27-31.

9 Allsopp M, Costner P, Johnston P. Incineration and human health. State of knowledge of the impacts of waste incinerators on human health (executive summary). ESPR-Environ Sci Pollut Res 2001;8:141-5.

10 Tong S, Short RV. Dizygotic twinning as a measure of human fertility. Hum Reprod 1998;13:95-8.

11 Kataki A. Kouvatsi A. Twinning in Greece. Acta Genet Med Gemellol (Roma) 1988;37:147-50.

12 James WH. Secular changes in twinning rates in England and Wales. Ann Hum Biol 1980;7:485-7.

13 Anon. Contribution of assisted reproductive technology and ovulationinducing drugs to triplet and higher-order multiple births-United States, 1980-1997. MMWR Morb Mortal Wkly Rep 2000;49:535-8. 
14 Corchia C, Mastroiacovo $\mathrm{P}$, Lanni R, et al. What proportion of multiple births are due to ovulation induction? A register-based-study in Italy. Am J Public Health 1996;86:851-4.

15 Elster N. Less is more: the risks of multiple births. The Institute for Science, Law, and Technology Working Group on Reproductive Technology. Fertil Steril 2000;74:617-23.

16 Blondel B, Kogan MD, Alexander GR, et al. The impact of the increasing number of multiple births on the rates of preterm birth and low birthweight: an international study. Am J Public Health 2002;92:1323-30.

17 Glinianaia SV, Rankin J, Renwick M. Time trends in twin perinatal mortality in northern England, 1982-94. Northern Region Perinatal Mortality Survey Steering Group. Twin Res 1998;1:189-95.

18 Osius N, Karmaus W. Reproduktions-Epidemiologischer Untersuchungsteil des Human-Biomonitoring Südhessen (1. Survey 1994/95). Report M. Wiesbaden, Hessisches Sozialministerium, 1998.

19 Heller G, Misselwitz B, Schmidt S. Early neonatal mortality, asphyxia related death, and timing of low risk births in Hesse, Germany, 1990-8: observational study. BMJ 2000;321:274-5.

20 Karmaus W, Juul S. Infertility and subfecundity in population-based samples from Denmark, Germany, Italy, Poland and Spain. Eur J Public Health 1999;9:229-35

21 Künzel W. The birth survey in Germany-education and quality control in perinatology. Eur J Obstet Gynecol Reprod Biol 1994;54:13-20.

22 SAS Institute Inc. SAS/STAT. SAS system release 6.12. Cary, NC: SAS Institute Inc., 1996.
23 SPSS Inc. SPSS for Windows base system user's guide. Release 6.0. Chicago: SPSS Inc., 1993.

24 Platt MJ, Marshall A, Pharoah PO. The effects of assisted reproduction on the trends and zygosity of multiple births in England and Wales 1974-99. Twin Res $2001 ; 4: 417-21$

25 Jones PW. Twinning in human populations and in cattle exposed to air pollution from incinerators. Br J Ind Med 1989;46:215-16.

26 Van Larebeke N. Health effects of a household waste incinerator near Wilrijk, Belgium. In: Nicolopoulou-Stamati P, Hens CV, Howard PL, eds. Health impact of waste management policies. In: Proceedings of the seminar "Health Impact of Waste Management Policies". Kos, Greece, Hippocrates Foundation, 12 11-1998. Kluwer Academic Publishers, 2000.

27 Carpenter DO, Shen Y, Nguyen T, et al. Incidence of endocrine disease among residents of New York areas of concern. Environ Health Perspect 2001;109:845-51.

28 Brucker-Davis F, Thayer K, Colborn T. Significant effects of mild endogenous hormonal changes in humans: considerations for low-dose testing. Environ Health Perspect 2001;109:21-6.

29 Damstra T. Potential effects of certain persistent organic pollutants and endocrine disrupting chemicals on the health of children. $J$ Toxicol Clin Toxicol 2002;40:457-65

30 Lambalk CB, Schoemaker J. Hypothetical risks of twinning in the natural menstrual cycle. Eur J Obstet Gynecol Reprod Biol 1997:75:1-4.

31 Montgomery GW, Duffy DL, Hall J, et al. Mutations in the follicle-stimulating hormone receptor and familial dizygotic twinning. Lancet 2001;357:773-4.

Answers to multiple choice questions on Mobile phone use and cancer by M Kundi, on pages $560-570$

(1) (a) true; (b) true; (c) false; (d) false; (e) false

(2) (a) true; (b) false; (c) false; (d) true; (e) false

(3) (a) false; (b) false; (c) true; (d) false; (e) true

(4) (a) false; (b) true; (c) false; (d) true; (e) false

(5) (a) false; (b) false; (c) true; (d) false; (e) false 